\title{
Gisèle Mathieu-Castellani, Le Rossignol poète dans l'Antiquité et à la Renaissance
}

\section{Maurizio Busca}

\section{(2) OpenEdition}

\section{Journals}

\section{Edizione digitale}

URL: http://journals.openedition.org/studifrancesi/5300

DOI: $10.4000 /$ studifrancesi. 5300

ISSN: 2421-5856

\section{Editore}

Rosenberg \& Sellier

\section{Edizione cartacea}

Data di pubblicazione: 1 dicembre 2016

Paginazione: 519

ISSN: 0039-2944

\section{Notizia bibliografica digitale}

Maurizio Busca, « Gisèle Mathieu-Castellani, Le Rossignol poète dans l'Antiquité et à la Renaissance »,

Studi Francesi [Online], 180 (LX | III) | 2016, online dal 01 janvier 2017, consultato il 18 septembre 2020. URL : http://journals.openedition.org/studifrancesi/5300; DOI : https://doi.org/10.4000/studifrancesi. 5300

Questo documento è stato generato automaticamente il 18 settembre 2020.

\section{(c) $(1)$}

Studi Francesi è distribuita con Licenza Creative Commons Attribuzione - Non commerciale - Non opere derivate 4.0 Internazionale. 


\title{
Gisèle Mathieu-Castellani, Le Rossignol poète dans l'Antiquité et à la Renaissance
}

\author{
Maurizio Busca
}

\section{NOTIZIA}

GISÈLE MATHIEU-CASTELLANI, Le Rossignol poète dans l'Antiquité et à la Renaissance, Paris, Classiques Garnier, 2016, «Études et essais sur la Renaissance» 112, 235 pp.

1 Personaggio del mito e oggetto di indagine scientifica, soggetto prediletto dai poeti e metafora della figura stessa del poeta, l'usignolo è una presenza familiare nelle opere dell'Antichità greco-latina così come del Rinascimento e del Barocco francese. Il presente volume, suddiviso secondo un criterio cronologico in due parti (Le chantre rossignol dans l'Antiquité, pp. 13-86, e Le chantre rossignol à la Renaissance et à l'âge baroque, pp. 87-213) ognuna delle quali articolata in una serie di capitoli tematici, costituisce un agile repertorio ragionato delle occorrenze del cantore alato nelle letterature prese in considerazione.

2 La prima parte si apre con una recensione delle diverse varianti dei due miti classici in cui compare l'usignolo: quello di Aedo, figlia di Pandareo, e quello ben più noto di Filomela, Procne e Tereo. Gli antichi non sono concordi nello stabilire quale delle figlie di Pandione fu trasformata in usignolo: per i greci è generalmente Procne, per i latini Filomela. Sarà la variante latina ad imporsi nel Cinquecento, soprattutto in virtù della fortunatissima versione data da Ovidio nelle sue Metamorfosi, oggetto di rifacimenti già dal Medioevo. Non soltanto i mitografi, ma anche gli scienziati e i filosofi dell'Antichità, da Aristotele ad Agostino, si interessano all'uccelletto e in particolare alla sua abilità nel canto (dono innato o acquisito?), intorno alla quale fioriscono riflessioni che saranno ampiamente riprese nel Rinascimento. Dopo aver collocato l'usignolo nel quadro del mito e della storia naturale, l'A. ne percorre le incarnazioni nelle opere dei 
poeti greci (ivi compresi i tragici e i comici), presso i quali il suo canto diviene «à la fois l'emblème du chant amoureux séduisant l'oreille, et celui de la plainte élégiaque propre à émouvoir» (p.64). I poeti latini prediligeranno invece gli accenti tragici dell'inimitabile voce dell'uccello, spesso evocato in riferimento alla storia dell'infelice Filomela.

La seconda parte, dedicata al Cinquecento e al primo Seicento francese, è introdotta da un capitolo in cui vengono messi in luce i principali modelli italiani, in primo luogo Petrarca e Bembo, della topica assimilazione/rivalità fra la figura del poeta e quella del «chantre oisillon» (Baif) ampiamente trattata da Ronsard e dai poeti della Brigade. Nella poesia di ispirazione ronsardiana, come più tardi nella poesia manierista, l'usignolo è inoltre frequentemente associato all'arrivo della primavera; tuttavia il ruolo di annunciatore della stagione degli amori è talvolta condiviso con (o assunto da) la rondine, cioè quello stesso uccello che, presso gli antichi, contendeva all'usignolo l'esito della metamorfosi di Filomela (o di Procne). La poesia cinquecentesca associa al canto del «mignon rossignol» tutta una serie di emozioni e stati psicologici, anche discordanti - quando non completamente opposti: dalla melancolia più mesta, a quella più dolce e languida, alla gioiosa spensieratezza. Tale varietà di toni ben si presta ad essere sfruttata nel trattamento di una tematica polivalente come quella amorosa, dacché il canto «mêlé d'amour et d'un peu de tristesse» può sia incantare che affliggere l'amante che lo ascolta. I poeti dell'epoca rinascimentale e barocca non dimenticano, peraltro, il mito di Filomela e Procne, diverse volte riscritto e menzionato in numerosi componimenti in cui la voce dell'usignolo è connotata da note luttuose. L'ultimo capitolo della sezione concerne i meriti propriamente musicali che vengono riconosciuti al «parfait Chanteur» (Marot), in particolare la dolcezza e l'inimitabile varietà delle sue modulazioni canore, mentre le pagine conclusive forniscono un utile glossario (corredato di un ricco corpus di citazioni) dei termini tecnici impiegati nella letteratura dell'epoca per descriverne il canto. 